\title{
Laser ignitability of insensitive propellants
}

\author{
Xiao Fang* and Sheikh R. Ahmad \\ Centre for Defence Chemistry, Cranfield University, Defence Academy of the UK, Shrivenham, Swindon SN6 8LA, UK
}

\begin{abstract}
Laser ignition tests were conducted on insensitive propellants formulated with an insensitive filler (1,1-diamino-2,2-dinitroethylene, commercially known as FOX7) and with either energetic or non-energetic binders: poly3-nitromethyl-3-methyloxetane (PolyNIMMO) and hydroxyl-terminated polybutadiene (HTPB), respectively. The tests were conducted in an unconfined environment using both visible $(514 \mathrm{~nm})$ and near infrared ( $808 \mathrm{~nm})$ lasers. The non-energetic binder rendered the formulated ammunition more susceptible to initiation by the visible laser. The graph of ignition delay times versus laser power density followed the expected asymptotic trend. However, the shape of the ignition map was greatly affected by the beam area on the target. The results of the unconfined laser ignition tests were analysed to determine the feasibility of using lasers as cost-effective and safe igniters for future weapons and rocket motor systems.
\end{abstract}

\begin{abstract}
Abbrevations: CW: continuous wave; FOX-7: 1,1 diamino-2,2dinitroethylene; HMX: 1,3,5,7-Tetranitro-1,3,5,7-tetrazocane; HTPB: hydroxyl-terminated polybutadiene; NIR: near infrared; NTO: 3-nitrotriazol-5-one; PolyNIMMO: poly3-nitromethyl-3-methyloxetane; RDX: 1,3,5-Trinitro-1,3,5-triazinane; TATB: 1,3,5-triamino-2,4,6-trinitrobenzene; UV: ultraviolet; VIS: visible
\end{abstract}

\section{Introduction}

Although maximum explosive or combustion performance is desirable for the use of energetic materials, two other factors have gained prominence in the context of new propellant formulations [1]. These are safety during storage, use and transportation, and the impact on the environment during the manufacturing and disposal of such materials. Consequently, emphasis has shifted to the production of high-performance and insensitive energetic materials complemented by safety and cost-effectiveness throughout the life cycle, as well as environmentally friendly disposal. The search for propellants that satisfy such requirements has led to the inclusion of both energetic and non-energetic plasticizers and binders in formulations based on nitramines such as RDX (1,3,5-Trinitro-1,3,5-triazinane) and HMX (1,3,5,7-Tetranitro-1,3,5,7-tetrazocane), to allow the replacement of conventional nitrocellulose-based propellants. Furthermore, insensitive explosives such as TATB (1,3,5-triamino-2,4,6-trinitrobenzene), FOX7 (1,1 diamino-2,2-dinitroethylene) and NTO (3-nitrotriazol-5-one) have been reformulated to replace the more sensitive nitramines used as energetic fillers. The reduced response to accidental stimuli means that such propellants are difficult to ignite using conventional bridgewire electric stimuli. This causes 'non-ideal ignition' thus reducing accuracy and leading to misfires, hang-fires and the catastrophic failure of gun systems, which is a major drawback of such propellant based systems at present.

The challenges listed above could be addressed by using directed optical energy from lasers to ignite energetic materials [2-8]. Highpower pulsed lasers such as ruby laser and Nd-YAG laser have been shown to initiate combustion [9-10]. The kinetics of optical energy transfer and its effect on energetic materials and pyrotechnics under laser irradiation have been modelled [11-12]. Although recent reports address the effects of various parameters on the kinetics and dynamics of laser interactions with energetic materials, particularly with pyrotechnics [13-15], in-service laser ignition system has not been described in the open literature.

The direct laser ignition of propellants and explosives, particularly insensitive energetic materials, has not been reported as widely as that for pyrotechnics. For propellants, the ignition threshold and ignition delay appear to be dependent on laser parameters, the chemical composition of the charge and the pressure within the confinement $[11,12,16]$. The effect of laser parameters has been minimized by the addition of carbon black [10]. The ignitability is inversely related to the surface ignition temperature of the burning materials. This resulted in the following order of ignitability for three test materials: double base (260-340 $\left.{ }^{\circ} \mathrm{C}\right)$, AP composite $\left(700-800^{\circ} \mathrm{C}\right)$ and $\operatorname{HMX}\left(1050^{\circ} \mathrm{C}\right)$ [17]. The ignition temperature of crystals in a composite formulation is greatly affected by the final ignition temperature of the binder. However, to the best of our knowledge the laser ignitibility of insensitive propellants formulated with insensitive high explosives as fillers has not been reported. This paper presents the results of initial tests on the laser ignitibility of propellants incorporating FOX-7 as an insensitive filler and HTPB or PolyNIMMO as non-energetic and energetic binders, respectively.

\section{Materials}

The insensitive propellants were formulated in-house as previously described [18] using the constituents listed in the Table 1. The filler RDX in the original formulation was replaced with FOX-7 due to its lower sensitivity than conventional RDX or HMX [19]. Two formulations were prepared (P1 and P2) by mechanical mixing, one with the energetic binder PolyNIMMO $\left[\mathrm{HO}-\left(\mathrm{C}_{5} \mathrm{NO}_{4} \mathrm{H}_{9}\right)_{n}-\mathrm{H}\right]$ and the other with the non-energetic binder HTPB $\left[\mathrm{HO}-\left(\mathrm{C}_{4} \mathrm{H}_{6}\right)_{\mathrm{n}}-\mathrm{OH}\right]$. The

*Correspondence to: Xiao Fang, Centre for Defence Chemistry, Cranfield University, Defence Academy of the UK, Shrivenham, Swindon SN6 8LA, UK, Fax: +44 (0)1793 785772; E-mail: x.fang@cranfield.ac.uk

Key words: propellant, FOX-7, laser, ignition

Received: April 02, 2018; Accepted: April 23, 2018; Published: April 26, 2018 
chemical structures of FOX-7, PolyNIMMO and HTPB as well as RDX, cellulose acetate and nitrocellulose are shown in Figure 1.

\section{Experimental}

The samples were practically opaque. Therefore, absorption spectra were recorded using a $150-\mathrm{mm}$ internal diameter integrating sphere (Lambda 9B013-8277) in a UV-VIS (200-850 nm) absorption spectrometer (Perkin Elmer, Model Lambda 9). We measured the total amount of light diffusely reflected from the surface over the solid angle of $2 \pi$ sr. The optical absorbance as a percentage of the incident flux density was expressed as $A(\lambda)=100-R(\lambda)$, where $R(\lambda)$ is the percentage reflectance.

The experimental setup for unconfined laser ignition tests is shown schematically in Figure 2. A solid aluminium block was prepared with a groove to hold the sample. For each test, the same amount $(5 \mathrm{mg})$ of sample in powder form was placed into the groove $(3 \mathrm{~mm}$ in diameter $\& 2 \mathrm{~mm}$ in depth) and was packed under the same pressure to minimize differences in measurement parameters caused by variations in sample density. The density of tested samples was $\sim 0.35 \mathrm{~g} \mathrm{~cm}^{-3}$.

For visible laser excitation, we used an Ar-ion laser (Spectra Physics, Model 165) operating in continuous wave (CW) mode at 514 $\mathrm{nm}$. The laser had a maximum power of $1.5 \mathrm{~W}$ over a beam area at the exit of $2.5 \mathrm{~mm}^{2}$ (beam divergence $0.5 \mathrm{mrad}$ ). For near infrared (NIR) excitation, we used a CW diode laser (HTOE, FLMM-0808) providing a maximum output of $5 \mathrm{~W}$ at $808 \mathrm{~nm}$. The laser beam was delivered to

Table 1: Formulation of the new propellant materials in this study

\begin{tabular}{|c|c|c|}
\hline $\begin{array}{c}\text { Formulation with non- } \\
\text { energetic binder (P1) }\end{array}$ & $\begin{array}{c}\text { Formulation with energetic } \\
\text { binder (P2) }\end{array}$ & Remarks \\
\hline HTPB $14 \%$ & PolyNIMMO $14 \%$ & Binder \\
\hline $\begin{array}{c}\text { FOX-7 } 78 \% \\
(\text { Grain size }=25 \mu \mathrm{m})\end{array}$ & $\begin{array}{c}\text { FOX-7 } 78 \% \\
(\text { Grain size }=25 \mu \mathrm{m})\end{array}$ & Filler \\
\hline Triacetin $6 \%$ & Triacetin $6 \%$ & Plasticizer \\
\hline Curing agent $2 \%$ & Curing agent $2 \%$ & \\
\hline
\end{tabular}<smiles>NC(N)=C([N+](=O)[O-])[N+](=O)[O-]</smiles>

FOX-7<smiles>CC(CO)(CO)CO[N+](=O)[O-]</smiles>

PolynimMo

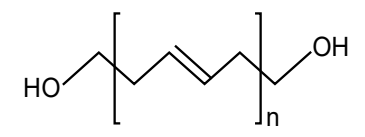

HTPB

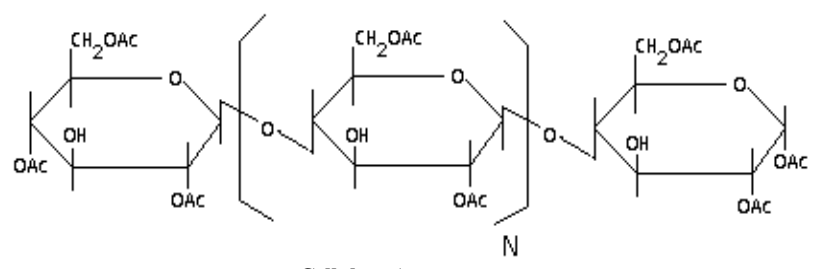

Cellulose Acetate

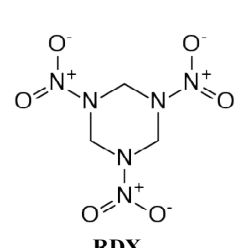

RDX

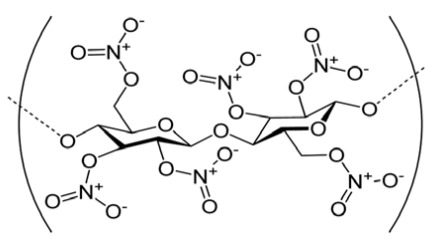

Nitrocellulose
Figure 1: Chemical structures of the components of the two insensitive propellant formulations and the original formulation

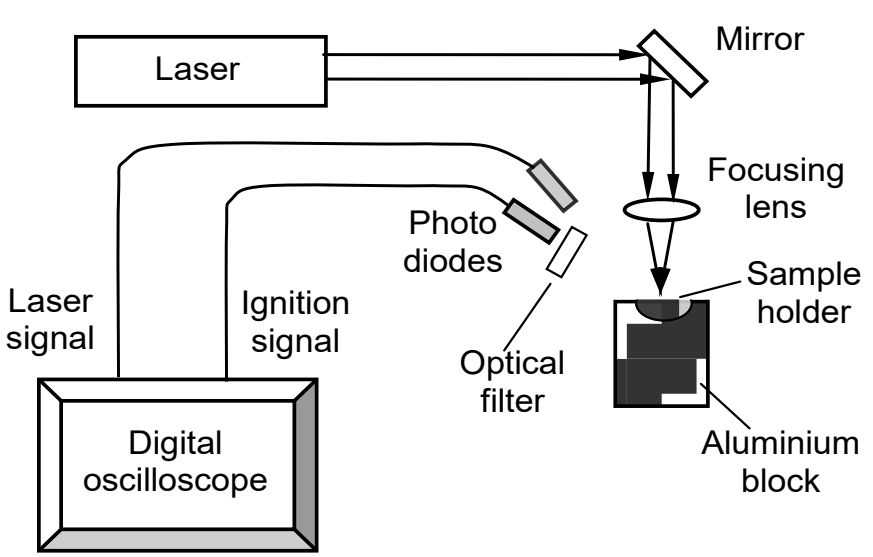

Figure 2: Schematic illustration of the experimental setup for unconfined laser ignition tests

the target surface via a $0.4-\mathrm{mm}$ diameter (cross-sectional area of 0.13 $\mathrm{mm}^{2}$ ) fibre-optic cable. The output of the beam had essentially a top hat profile due to the nature of beam propagation through the fibre-optic cable. The beam power was measured using a calibrated photodiode at the target, and the maximum value, after transmission losses, was 3.9 W. Two photodiodes (Centronic BPX65) were used to detect the laser and propellant combustion, respectively. The optical filter was placed on a photodiode to filter out the laser. A digitizing oscilloscope (Agilent Tech. DS5054A) was used to record the temporal history of the combustion.

\section{Results and Discussion}

The absorption spectra in Figure 3 show high absorbance at UV wavelengths below $300 \mathrm{~nm}$ for both propellant samples (P1 and P2). The absorbance of sample P1 decreased rapidly as the wavelength increased towards the visible region of $\sim 500 \mathrm{~nm}$ and was essentially constant at wavelengths beyond the visible range. The absorbance of sample P2 decreased rapidly from $\sim 400 \mathrm{~nm}$ to $600 \mathrm{~nm}$ and remained essentially constant at longer wavelengths. At the laser wavelengths considered in this study (514 $\mathrm{nm}$ and $808 \mathrm{~nm}$ ) the absorbance of sample P2 (61\% and $30 \%$, respectively) was greater than those of sample P1 (20\% and $12 \%$, respectively), thus $\mathrm{P} 2$ would be more susceptible to laser ignition.

Ignition tests were carried out under unconfined conditions using lasers operating at two widely different wavelengths, as previously reported for conventional double base and extruded propellants [12]. Figure 4 shows the oscilloscope trace for the laser and the laser-ignited flame of propellant sample P1. The interval between switching on the laser and observing the flame of ignition was recorded as the ignition delay time. Sustained ignition was observed when burning continued beyond the duration of the laser. Using the diode laser, sustained combustion was possible for both of the insensitive propellants and the power density for sustained ignition was $\geq 2.8 \mathrm{~kW} \mathrm{~cm}^{-2}$ (spot diameter $0.4 \mathrm{~mm}$ ), which approached the power density limit of the diode laser at the exit end of the cable. A smaller laser beam area, resulting in a higher power density, could have been achieved by collimating the beam before focusing, but this was not carried out during our experiment to avoid unacceptable reflection and absorption losses at and within the lenses. Furthermore, if the beam area is too small, the resulting high temperature tends to produce a crater in the target sample rather than the slower dissipation of heat throughout the sample to cause sustained ignition. The ignition was not always reproducible, and the ignition delay times were $1.5 \mathrm{~s}$ for P1 and $1.9 \mathrm{~s}$ for P2 at the heat flux density 
of $2.8 \mathrm{~kW} \mathrm{~cm} \mathrm{~cm}^{-2}$. Using the Ar-ion laser, the P2 sample could not be ignited at the maximum available power density of $8.5 \mathrm{~kW} \mathrm{~cm}{ }^{-2}$ with various laser beam diameters $(0.15-0.5 \mathrm{~mm})$ at the maximum power and exposure time of up to 5 seconds, but the P1 sample was readily ignited at and below this power density. Therefore an ignition map was constructed for the P1 propellant formulation. The P2 sample had an ignition threshold power which was higher than that could be provided in this study and thus was not studied further.

To evaluate the effect of the laser spot diameter on the ignitability of each sample, the ignition delay time was plotted against laser power densities with either a fixed beam area or a fixed laser power, as shown in Figure 5. Each experimental data point in the plot is an average over seven repeated tests, with the average root-mean-square errors of $\sim 12 \%$. The power density was changed by varying the laser power for the former and by varying the irradiated area (changing the focal distance of the lens) for the latter. The beam area had a significant impact on the ignition threshold value, the minimum power density that ignites the material. The measured values for the effect at ignition threshold in Fig. 5 are given in Table 2, including laser beam radius $\left(r_{o}\right)$ and area $(s)$, ignition delay $\left(t_{i}\right)$, and ignition threshold power density $\left(P_{t h}\right)$, energy density $\left(W_{t h}\right)$ and energy $\left(E_{t h}\right)$ for sustained combustion. As can be seen from the table, the ignitibility of the propellant increased

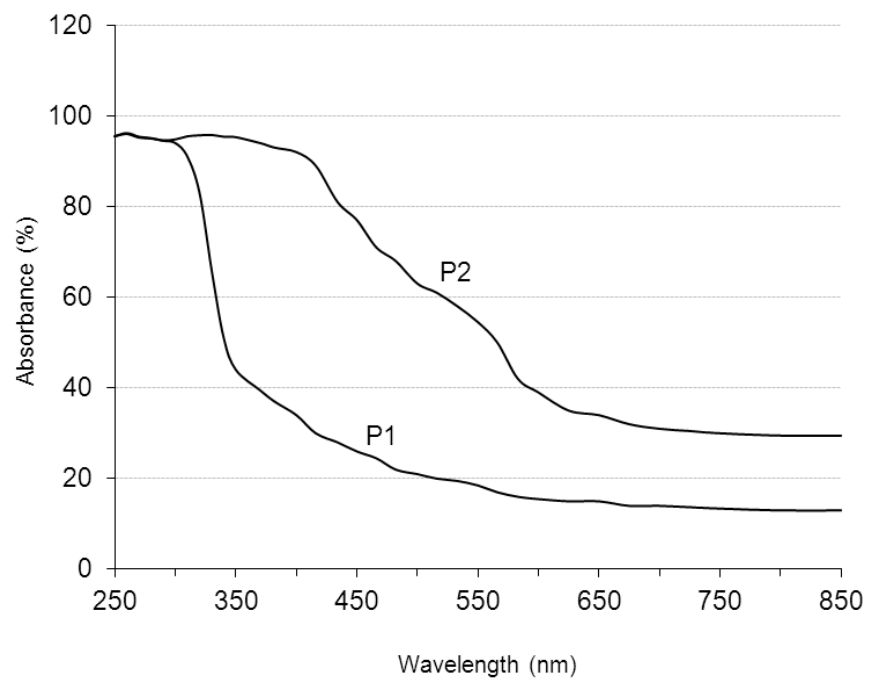

Figure 3: Absorption spectra of the insensitive propellants used in this study

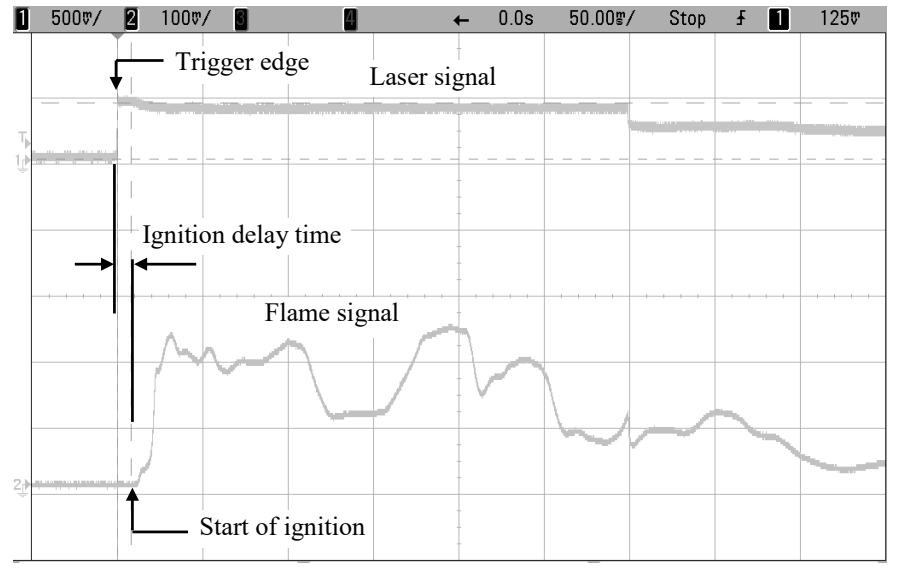

Figure 4. Oscilloscope traces of an ignition event to show the light signal from the igniting laser and the ignited flame from the propellant

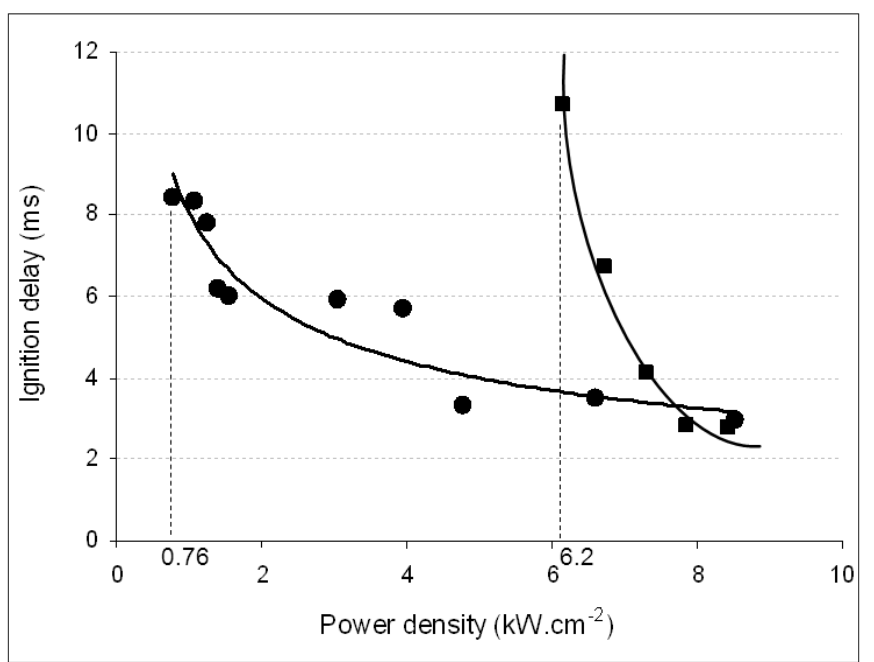

Figure 5: Ignition map using an Ar-ion laser for unconfined propellant sample P1: effect of laser spot area on the target. $(\bullet$ Fixed power $(1.5 \mathrm{~W}) /$ variable beam area, $\square$ Fixed beam area $\left(1.8 \times 10^{-4} \mathrm{~cm}^{2}\right) /$ variable power $)$

Table 2: Measurements at ignition thresholds in Figure 5

\begin{tabular}{|c|c|c|}
\hline \multirow{2}{*}{ Parameters } & \multicolumn{2}{|c|}{ Measurement } \\
\hline \multirow{2}{*}{$\boldsymbol{P}_{\boldsymbol{t h}}, \mathbf{k W} / \mathbf{c m}^{\mathbf{2}}$} & Wider laser beam & Narrower laser beam \\
\hline$t_{i}, \mathrm{~ms}$ & $\mathbf{0 . 7 6}$ & $\mathbf{6 . 2}$ \\
\hline$s, \mathrm{~cm}^{2}$ & 8.45 & 10.73 \\
\hline $\boldsymbol{r}_{\boldsymbol{o}}, \mathbf{c m}$ & $1.97 \times 10^{-3}$ & $1.8 \times 10^{-4}$ \\
\hline $\boldsymbol{W}_{\boldsymbol{t h}}=\boldsymbol{t}_{\boldsymbol{i}} \boldsymbol{P}_{\boldsymbol{t h}}, \mathbf{J} / \mathbf{c m}^{2}$ & $\mathbf{2 . 5} \times \mathbf{1 0}^{-\mathbf{2}}$ & $\mathbf{0 . 7 5} \times \mathbf{1 0}^{-\mathbf{2}}$ \\
\hline $\boldsymbol{E}_{\boldsymbol{t h}}=\boldsymbol{s} \boldsymbol{W}_{\boldsymbol{t} \boldsymbol{h}}, \mathbf{J}$ & $\mathbf{6 . 3 8}$ & $\mathbf{6 6 . 5 3}$ \\
\hline
\end{tabular}

by a factor of at least 8 in terms of threshold power density when the beam area increased by a factor of $\sim 11$ while the energy absorbed in the volume is approximately a constant. Fig. 5 also shows that the ignition delay times are significantly differed in the heat flux density range of around $1-7 \mathrm{~kW} / \mathrm{cm}^{2}$. This result may be attributed to the effect of the radial heat dissipation from the exothermic reaction zone in the laser irradiated sample surface. This radial heat dissipation caused the increase of ignition threshold, and the effect was greater for a smaller laser beam, as reported in Duginov's study [20]. The characteristic time of the radial heat removal from the absorption region of the light beam can be estimated using the expression

$$
\tau \sim r_{0}^{2} / a
$$

Where $\boldsymbol{r}_{\boldsymbol{0}}$ is the beam radius and $\boldsymbol{a}$ is the thermal diffusivity. With this equation a comparison of the characteristic times for the wide $(0.25$ $\mathrm{mm}$ radius) and narrow ( $0.075 \mathrm{~mm}$ radius) laser beams, as used for the threshold energy densities in Fig. 5, was calculated and showed much longer characteristic time ( $\sim 11$ folds) for the former. This effect is evidenced by the difference of approximately an order of magnitude in their threshold energy densities $\left(W_{t h}\right)$ as shown in Table 2. Therefore, at the same heat flux density, a larger laser beam may ignite the sample quicker than a smaller one due to its larger absorption region and thus slower heat dissipation, and the threshold power density may be lower for a larger laser ignition beam. It is also shown in Fig. 5 that when the heat flux density is increased by reducing the laser beam size, causing the increase of the effect, the ignition delay time decrease slower than when it was by increasing the laser power.

Our results suggest that the combustion mechanism is not substantially affected by the main chain scission of the binder 
molecules, given that the non-energetic binder HTBP with a high main chain bond energy of $607 \mathrm{~kJ} \mathrm{~mol}^{-1}$ was much easier to ignite than the energetic binder PolyNIMMO with a lower main chain bond energy of $347 \mathrm{~kJ} \mathrm{~mol}^{-1}$. The dynamics of laser ignition in complex systems such as insensitive materials can be difficult to explain in terms of the energy transfer model with a local thermal equilibrium. The temperature of a surface heated by laser can be determined using heat equation [21], which shows that the temperature rise due to laser ignition depends on both the optical properties (e.g. absorption) and thermal properties (conductivity and diffusivity) of the material. Therefore, our preliminary results suggest that the greater ignitability of sample P1 (non-energetic binder) compared to sample P2 (energetic binder) may reflect differences in their thermal properties, the values of which were not available for a quantitative discussion of the equation and would be investigated in future study.

\section{Conclusion}

A propellant formulation containing a non-energetic binder was more susceptible to laser ignition than a formulation containing an energetic binder, particularly when ignited with a visible laser rather than a NIR laser, given that the latter failed to ignite with Ar-ion laser although the absorption coefficient of the sample P1 with HTPB is less than the sample P2 containing an energetic binder. The greater optical sensitivity of the insensitive propellant containing the nonenergetic binder may reflect its thermal properties which could change the ignition mechanism of tested samples. Our results show that a laser ignition system for insensitive propellants must accommodate a compromise between the laser beam area and the laser power. Laser ignition threshold is lower and ignition time is shorter when a larger laser beam is used for ignition. Using Ar-Ion laser for ignition, the critical value of laser heat flux was $6.2 \mathrm{~kW} \mathrm{~cm}^{-2}$ for a $0.15 \mathrm{~mm}$ laser beam diameter and it was $0.76 \mathrm{~kW} \mathrm{~cm}^{-2}$ for a larger beam diameter of $0.5 \mathrm{~mm}$. Further research should consider the inclusion of optical sensitizers and ignition mechanism for the development of formulations suitable for the practical implementation of laser ignition for propellants.

\section{References}

1. Cumming AS, Paul NC (1998) Environmental issues of energetic materials: a UK perspective. Waste Management 17: 129-133.

2. Isler J (1998) The transition to insensitive munitions (IM). Prop Explos Pyrotech 23: 281-291.
3. Strakovsk LG, Ulyakov PI, Frolov EI (1997) Ignition of certain secondary explosives by laser radiation. 15th All-Union Symposium on Combustion and Detonation, Chernogolovka.

4. Deluca L, Caveny LH, Ohlemiller TJ, Summerfield M (1976) Radiative ignition of double-base propellants: I. Some formulation effects. AIAA J 14: 940-946.

5. Ulas A, Kuo KK (2008) Laser-induced ignition of solid propellants for gas generators. Fuel 87: 639-646.

6. Zennin AA, Zanotti C, Jiuliani P (2014) Characteristics of composite propellant ignition by a $\mathrm{CO}_{2}$ laser. $J$ Phys Chem $B$ 8: 475-484.

7. Fang X, Ahmad SR (2016) Laser ignition of an optically sensitized secondary explosive by a diode laser. Cent Eur J Energ Mater 13: 103-115.

8. De NN, Cummock NR, Gunduz IE, Tappan BC (2016) Photoflash and laser ignition of select high-nitrogen materials. Combust Flame 167: 207-217.

9. Ritchie SJ, Thynell ST, Kuo KK (1997) Modelling and experiments of laser-induced ignition of nitramine propellants. J Propul Power 13: 367-374.

10. Raun RL (2000) Modelling of ESD-induced confined ignition of solid rocket propellants. Combust Flame 120: 107-124.

11. March H (1993) Measurement of threshold energies for reliable ignition of solid propellants using a pulsed Nd-Glass laser. $14^{\text {th }}$ International Symposium on Ballistics, Quebec, Canada pp: 469-478.

12. Ahmad SR, Russell DA, Leach CJ (2001) Studies into laser ignition of unconfined propellants. Prop Explos Pyrotech 26: 235-245.

13. Opdebeck F, Gillard P, Radenac E (2001) Optimization of interface conditions in the case of laser diode ignition of pyrotechnic mixtures. Prop Explos Pyrotech 26: 196-200.

14. Ahmad SR, Russell DA (2005) Laser ignition of pyrotechnics - effects of wavelength, composition and confinement. Prop Explos Pyrotech 30: 131-139.

15. Lee A, Stringer M, Smit K (2003) Laser match head for pyrotechnic ignition. Technical Report DSTO-TR-1448, Weapon Systems Division, Australia.

16. Atwood AL, Price CF, Boggs TL (1991) Ignitability measurements of solid propellants International Annul Conference of ICT, $22^{\text {nd }}$ Karlsruhe, Germany pp: 44.1-44.15.

17. Kubota N, Ohlemiller TJ, Caveny LH, Summerfield M (1974) Site and mode of action of platonizers in double base propellants. AIAA J 12: 1709-1714.

18. Pillai AG, Sanghavi RR (2001) Studies on RDX particle size in LOVA gun propellant formulations. Prop Explos Pyrotech 26: 226-228.

19. Karlsson S (2002) Detonation and sensitivity properties of FOX-7 and formulations containing FOX-7. Proceeding of $12^{\text {th }}$ International Detonation Symposium, San Diego, California, pp: 286-291.

20. Duginov EV, Khaneft AV (2011) Effect of the temperature dependence of the absorption coefficient on the critical energy of ignition of condensed substances by a laser pulse. Combustion, Explosion, and Shock Waves 47: 490-497.

21. Ali AN, Son SF, Asay BW, Decroix ME, Brewster MQ (2003) High-irradiance laser ignition of explosives. Combust Sci Technol 175: 1551-1571.

Copyright: (C2018 Fang X. This is an open-access article distributed under the terms of the Creative Commons Attribution License, which permits unrestricted use, distribution, and reproduction in any medium, provided the original author and source are credited. 